\title{
Increased plasma membrane cholesterol in cystic fibrosis cells correlates with CFTR genotype and depends on de novo cholesterol synthesis
}

\author{
Danjun Fang ${ }^{+1}$, Richard H West ${ }^{+1}$, Mary E Manson 1 , Jennifer Ruddy2 , Dechen Jiang ${ }^{1}$, Stephen F Previs3 \\ Nitin D Sonawane ${ }^{1,4}$, James D Burgess ${ }^{1}$ and Thomas J Kelley*2
}

\begin{abstract}
Background: Previous observations demonstrate that Cftr-null cells and tissues exhibit alterations in cholesterol processing including perinuclear cholesterol accumulation, increased de novo synthesis, and an increase in plasma membrane cholesterol accessibility compared to wild type controls. The hypothesis of this study is that membrane cholesterol accessibility correlates with CFTR genotype and is in part influenced by de novo cholesterol synthesis.

Methods: Electrochemical detection of cholesterol at the plasma membrane is achieved with capillary microelectrodes with a modified platinum coil that accepts covalent attachment of cholesterol oxidase. Modified electrodes absent cholesterol oxidase serves as a baseline control. Cholesterol synthesis is determined by deuterium incorporation into lipids over time. Incorporation into cholesterol specifically is determined by mass spectrometry analysis. All mice used in the study are on a C57BI/ 6 background and are between 6 and 8 weeks of age.

Results: Membrane cholesterol measurements are elevated in both $\mathrm{R} 117 \mathrm{H}$ and $\triangle \mathrm{F} 508$ mouse nasal epithelium compared to age-matched sibling wt controls demonstrating a genotype correlation to membrane cholesterol detection. Expression of wt CFTR in CF epithelial cells reverts membrane cholesterol to WT levels further demonstrating the impact of CFTR on these processes. In wt epithelial cell, the addition of the CFTR inhibitors, Gly H101 or $\mathrm{CFTR}_{\text {inh }}-172$, for $24 \mathrm{~h}$ surprisingly results in an initial drop in membrane cholesterol measurement followed by a rebound at $72 \mathrm{~h}$ suggesting a feedback mechanism may be driving the increase in membrane cholesterol. De novo cholesterol synthesis contributes to membrane cholesterol accessibility.
\end{abstract}

Conclusions: The data in this study suggest that CFTR influences cholesterol trafficking to the plasma membrane, which when depleted, leads to an increase in de novo cholesterol synthesis to restore membrane content.

\section{Background}

Recent studies have identified alterations in cholesterol processing associated with cystic fibrosis (CF) [1-4]. The hypothesis of this study is that plasma membrane cholesterol accessibility as measured by electrochemical detection will correlate with CFTR genotype. Identifying this relationship between this cholesterol measurement and CFTR will help determine if this measurement can be

\footnotetext{
* Correspondence: thomas.kelley@case.edu

2 Department of Pediatrics and Pharmacology, Case Western Reserve University, Cleveland, OH 44106, USA

+ Contributed equally
}

Full list of author information is available at the end of the article potentially utilized as a biomarker of CF. With the development of new therapies targeting CFTR function, new methods of identifying efficacy are needed that are reliable and non-invasive. Mechanistically, it is proposed that rates of de novo cholesterol synthesis influence the membrane cholesterol measurement.

The cystic fibrosis transmembrane conductance regulator (CFTR) is a cAMP activated chloride channel of the ATP binding cassette $(A B C)$ family [5,6]. A structurally similar protein within this family, $A B C A 1$, is known to mediate cholesterol transport across the plasma membrane to high-density lipoprotein (HDL) $[7,8]$. The role of 
CFTR function in regulating cholesterol transport is unclear, particularly with respect to how plasma membrane cholesterol is regulated. It has been observed that cultured CF cells, as well as nasal and tracheal epithelium from CFTR null mice, exhibit a significant increase in plasma membrane cholesterol accessibility [3]. Although structurally similar to $\mathrm{ABCA1}$, there is no evidence that CFTR is capable of directly modulating cholesterol movement. We have previously demonstrated that de novo cholesterol synthesis is elevated in the lungs of $\mathrm{Cftr}-/$ mice [3]. Evidence does suggest that membrane cholesterol content can be regulated by de novo synthesis $[9,10]$. Koter et al demonstrate that statin treatment reduces membrane cholesterol content in erythrocytes from 2.24 +/- 1.69 to $1.17+/-0.75 \mathrm{mg}$ cholesterol $/ \mathrm{mg}$ protein, a $47 \%$ reduction [9]. It is possible that increased membrane cholesterol in CF plasma membrane is related to increased de novo cholesterol synthesis.

Regardless of whether cholesterol processing changes observed in CF cells and tissues are directly involved in the pathology of CF, these cholesterol changes are potentially good, accessible indirect markers of CF-related cell signaling. The goal of this study is to determine if CFTR genotype correlates with plasma membrane cholesterol detection and to determine if de novo cholesterol synthesis contributes to this measure. Data demonstrate a clear CFTR genotype correlation with $\triangle F 508$ CFTR mice exhibiting higher membrane cholesterol content and increased de novo cholesterol synthesis relative to $\mathrm{R} 117 \mathrm{H}$ CFTR mice. Other studies demonstrate the relationship between membrane cholesterol and CFTR by examining restoration of wt CFTR in CF epithelial cells and examining the impact of acute CFTR inhibition.

\section{Methods \\ Cell culture}

Human epithelium 9/HTEo-cells over expressing the CFTR R domain (pCEPR) and mock-transfected 9/ HTEo-cells (pCEP), the wild type phenotype, were a generous gift from the lab of Dr. Pamela B. Davis (Case Western Reserve University). Cells were cared for as previously described [11]. IB3-1 cells, human epithelial with the delta F508 mutation (CF-phenotype), and S9 cells, IB3-1 cell stably transfected with the full-length wt CFTR (control) were a generous gift from Pamela L. Zeitlin (Johns Hopkins University, Baltimore, MD). These cells were grown at $37^{\circ} \mathrm{C}$ in $95 \% \mathrm{O}_{2}-5 \% \mathrm{CO}_{2}$ on Falcon 10 $\mathrm{cm}$ diameter tissue culture dishes in LHC-8 Basal Medium (Biofluids Camarillo, CA) with 5\% FBS.

\section{Mice}

Mice homozygous for the $\triangle \mathrm{F} 508$ CFTR mutation were described previously [12], as were mice carrying the
R117H CFTR mutation [13]. Mice heterozygous for CFTR expression ( $\left.\mathrm{Cftr}_{\text {tmlUnc }}\right)$ were obtained from Jackson Laboratories (Bar Harbor, MA). All mice were provided by the CF Center animal core facility at Case Western Reserve University. CFTR wild-type mice were siblings of $C f t r+/$ - mice. All mice were used between six and eight weeks of age. All mice were used between six and eight weeks of age and are back-crossed over ten generations onto a C57Bl/6 background. Mice were cared for in accordance with the Case Western Reserve University IACUC guidelines by the CF Animal Core Facility.

\section{Electrochemical measurements of cholesterol}

Platinum microelectrodes are fabricated in house $(4 \mu \mathrm{m}$ diamter wire for cell work and $100 \mu \mathrm{m}$ diameter wire for tissue measurements, Goodfellow Corp.) as described $[14,15]$. Platinum wire is inserted into glass capillaries (Kimax-51, Kimble products) and placed inside a heated platinum coil. The glass is pulled to create a thin insulating layer on the platinum wire. The capillary microelectrodes are polished using a beveling machine (WPI, Inc.) to produce a disk electrode. The microelectrodes are immediately immersed in a $5 \mathrm{mM}$ hexane solution of 11mercaptoundecanoic acid (95\%, Aldrich Chem. Co) for 2 $\mathrm{h}$ to form a carboxylic acid terminated monolayer on the electrode surface. Then, the microelectrodes are treated 2 $\mathrm{mM}$ 1-ethyl-3-(3-dimethylaminopropyl) carbodiimide (EDC) (Sigma Chem. Co.) in $100 \mathrm{mM}$ PBS solution (pH 7.4) for $30 \mathrm{~min}$. to activate the carboxyl groups to an acylisourea intermediate. The modified electrode is immersed in $1 \mathrm{mg} / \mathrm{ml}$ recombinant cholesterol oxidase (WAKO Chemical USA, Inc., 42.0 units/mg) solution for 3 hrs allowing this intermediate to react with amine immobilizing the enzyme on the electrode surface.

\section{Data Acquisitions}

Amperometric measurements are conducted using a two-electrode cell and a voltammeter-amperometer (Chem-Clamp, Dagan corp.). The three-pole Bessel filter in the voltammeter-amperometer is set to $100 \mathrm{~Hz}$. The output is further processed using a noise-rejecting voltmeter (model 7310 DSP, Signal Recovery Inc.) to digitally filter $60-\mathrm{Hz}$ noise. $\mathrm{An} \mathrm{Ag} / \mathrm{AgCl}(1 \mathrm{molar} \mathrm{KCl})$ reference electrode is used for all experiments, and the applied potential is $780 \mathrm{mV}$ versus NHE for all experiments. All experiments are performed in $100 \mathrm{mM}$ phosphate buffer $(\mathrm{pH} 7.4)$ at $36^{\circ} \mathrm{C}$. Single cells and excised tissue are captured by a capillary prepared in house using an IM-6 microinjector (Narishige International USA, Inc.). The electrode is initially positioned about $50 \mu \mathrm{m}$ from the cell surface or tissue inner edge for acquisition of baseline data. The electrode is repositioned for contacting the biological sample and acquisition of electrode response. 


\section{Measuring cholesterol synthesis in vivo}

$C F T R_{\text {tm1 } 1 \text { nc }}$ mice and the matched controls were given an intraperitoneal injection (i.p.) $(\sim 24 \mu \mathrm{l}$ per g body weight) of deuterated saline $(9 \mathrm{~g} \mathrm{NaCl}$ in $1000 \mathrm{ml}$ of $99 \% 2 \mathrm{H} 2 \mathrm{O}$, Sigma-Aldrich, St. Louis, MO). After 8 h, mice were sacrificed using carbon dioxide. Blood was taken from the heart and plasma collected. Whole lungs were collected. Tissue samples were hydrolyzed in $1 \mathrm{~N} \mathrm{KOH} / 70 \%$ ethanol $(\mathrm{v} / \mathrm{v})$ for 2 at $70^{\circ} \mathrm{C}$ vortexing occasionally. Samples were then evaporated to dryness, redissolved in $2 \mathrm{ml}$ of water and acidified using $12 \mathrm{~N} \mathrm{HCl}$. Cholesterol was extracted twice by addition of ethyl ether $(3 \mathrm{ml})$. The pooled ether extracts were evaporated to dryness under nitrogen and then converted to the trimethylsilyl cholesterol derivatives by reacting with $60 \mu \mathrm{l}$ of bis(trimethylsilyl) trifluoroacetamide $+1 \%$ trimethylchlorosilane (Regis, Morton Grove, IL) (TMS) at $60^{\circ} \mathrm{C}$ for $20 \mathrm{~min}$. The $2 \mathrm{H}$-labeling of cholesterol was determined using an Agilent 5973NMSD equipped with an Agilent 6890 GC system. The cholesterol was run on a DB17-MS capillary column (30 $\mathrm{m} \times 0.25 \mathrm{~mm} \times 0.25 \mu \mathrm{m})$. The oven temperature was initially held for $1 \mathrm{~min}$ at $150^{\circ} \mathrm{C}$, then increased by $20^{\circ} \mathrm{C}$ per min to $310^{\circ} \mathrm{C}$ and maintained for $8 \mathrm{~min}$. The split ratio was 20:1 with helium flow $1 \mathrm{ml}$ per min. The inlet temperature was set at $270^{\circ} \mathrm{C}$ and MS transfer line was set at $310^{\circ} \mathrm{C}$. Under these conditions, cholesterol elutes at $\sim 11.1$ $\mathrm{min}$. Electron impact ionization was used in all analyses with selected ion monitoring of $\mathrm{m} / \mathrm{z}$ 368-372 (M0-M4, cholesterol), dwell time of $10 \mathrm{~ms}$ per ion.

The ${ }^{2} \mathrm{H}$-labeling of mice plasma water was determined by exchange with acetone. Briefly, plasma was diluted 2fold with distilled water and reacted with $2 \mu \mathrm{l}$ of $10 \mathrm{~N}$ $\mathrm{NaOH}$ and $4 \mu \mathrm{l}$ of a $5 \%(\mathrm{v} / \mathrm{v})$ solution of acetone in acetonitrile for $24 \mathrm{~h}$. Acetone was extracted by addition of $600 \mu \mathrm{l}$ of chloroform followed by addition of $0.5 \mathrm{~g}$ $\mathrm{Na}_{2} \mathrm{SO}_{4}$. Samples were vigorously mixed and a small aliquot of the chloroform was transferred to a GC-MS vial. Acetone was analyzed using Agilent equipment described above. The oven temperature program was: $60^{\circ} \mathrm{C}$ initial, increase by $20^{\circ} \mathrm{C}$ per min to $100^{\circ} \mathrm{C}$, increase by $50^{\circ} \mathrm{C}$ per min to $220^{\circ} \mathrm{C}$ and maintain for $1 \mathrm{~min}$. The split ratio was 40:1 with a helium flow of $1 \mathrm{ml}$ per min. The inlet temperature was set at $230^{\circ} \mathrm{C}$ and the mass spectrometer transfer line was set at $245^{\circ} \mathrm{C}$. Acetone eluted at $\sim 1.5 \mathrm{~min}$. The mass spectrometer was operated in the electron impact mode $(70 \mathrm{eV})$. Selective ion monitoring of $\mathrm{m} / \mathrm{z} 58$ and 59 was performed using a dwell time of $10 \mathrm{~ms}$ per ion.

\section{Calculation of cholesterol synthesis}

Protocols followed in [3] were used. Briefly, rates of de novo cholesterol synthesis were calculated using the for- mula: Total labeling $\left(\left[\left(\mathrm{M}_{1} \times 1\right)+\left(\mathrm{M}_{2} \times 2\right)+\left(\mathrm{M}_{3} \times 3\right)+\left(\mathrm{M}_{4}\right.\right.\right.$ $\times 4)]) / \mathrm{n} /{ }^{2} \mathrm{H}$-labeling of plasma water $\times$ time where $\mathrm{M} i$ represents isotope labeled isomeric species of cholesterol $\left(M_{1}\right.$ being singly labeled, $M_{2}$ doubly labeled) and "n" represents the number of exchangeable hydrogens, assumed to be 25 for cholesterol.

\section{Synthesis of Inactive-CFTR inh $-172: 5-(\mathrm{N}, \mathrm{N}-$ \\ dimethylphenyl)methylene)-2-thioxo-3-[3- (trifluoromethyl)phenyl]-4-thiazolidinone}

Mixture of 2-thioxo-3-(3-trifluoromethyl phenyl)-4-thiazolidinone $(110 \mathrm{mg}, 0.4 \mathrm{mM}$, synthesized according to Sonawane et al., [16], 4-(N,N-dimethyl)benzaldehyde (59 $\mathrm{mg}, 0.4 \mathrm{mM})$, and sodium acetate $(50 \mathrm{mg})$ in glacial acetic acid $(1 \mathrm{ml})$ was refluxed for $4 \mathrm{~h}$. Solvent was evaporated, residue dissolved in ethyl acetate, filtered, and silica gel (1 g) was added. Compound on silica gel was purified by normal phase flash chromatography to yield $68 \mathrm{mg}$ yellow-orange crystals (yield 42\%); mp: 224-226 ${ }^{\circ} \mathrm{C}$; MS $(\mathrm{ES}+)(\mathrm{m} / z):[\mathrm{M}+\mathrm{H}]_{+}$calculated for $\mathrm{C}_{19} \mathrm{H}_{15} \mathrm{~F}_{3} \mathrm{~N}_{2} \mathrm{OS}_{2}$, 409.4, found 409.3.

\section{Results}

\section{Membrane cholesterol genotype comparison}

Previous work has demonstrated that cultured cell models of CF and nasal and tracheal epithelium from Cftr -/mice exhibit an increase in membrane cholesterol content $[3,17]$. In order to determine if membrane cholesterol measurement correlates with Cftr genotype, membrane cholesterol was measured in nasal epithelium isolated from mice homozygous for either the $\mathrm{R} 117 \mathrm{H}(\mathrm{R} /$ $\mathrm{R})$ or the $\Delta \mathrm{F} 508(\Delta \mathrm{F} / \Delta \mathrm{F})$ CFTR mutations. Membrane cholesterol content as measured by response ratio is elevated in both $\mathrm{R} / \mathrm{R}$ and $\Delta \mathrm{F} / \Delta \mathrm{F}$ nasal epithelium $(1.64+/-$ $0.09(\mathrm{R} / \mathrm{R}), \mathrm{p}<0.001 ; 2.14+/-0.10(\Delta \mathrm{F} / \Delta \mathrm{F}), \mathrm{p}=0.01)$ compared to age-matched sibling wt controls (Figure 1). These data demonstrate that either a mild or severe disease related CFTR mutation will result in an increase in membrane cholesterol, with a larger magnitude increase in the $\Delta \mathrm{F} / \Delta \mathrm{F}$ tissue. The magnitude increase in membrane cholesterol in $\Delta \mathrm{F} / \Delta \mathrm{F}$ mouse nasal tissue is identical to what is observed in Cftr -/- nasal tissue [3]. This measurement does not determine absolute cholesterol content, only cholesterol accessible to the electrode at the outer leaflet of the plasma membrane. This increased accessibility could be due to increased total content, cholesterol displacement from the lipid bilayer, or efflux. These data demonstrate that membrane cholesterol measurements can differentiate between genotypes. WT mice from the $\Delta \mathrm{F} 508$ colony and the $\mathrm{R} 117 \mathrm{H}$ colony were directly compared and no difference in membrane cholesterol measurement was observed. 
A.

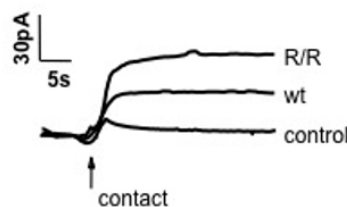

C.

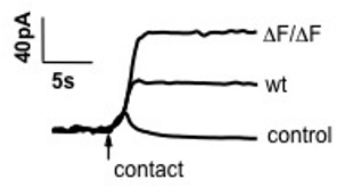

E.

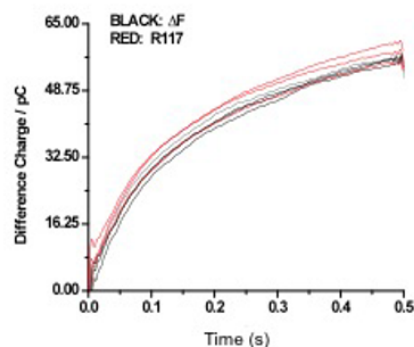

Figure 1 Electrochemical determination of membrane cholesterol content from mouse nasal epithelium. A, C) Representative traces of membrane cholesterol determination in excised nasal epithelium from Cftr R117H/R117H (R/R) mice and Cftr $\triangle \mathrm{F} 508 / \Delta \mathrm{F} 508$ ( $\triangle \mathrm{F} / \Delta \mathrm{F})$ mice, respectively, compared to sibling $C f t r+/+$ (wt) mice. B, D) Quantification of responses between $\mathrm{Cftr} R / \mathrm{R}$ and sibling $\mathrm{Cftr}+/+$ (wt) nasal tissue and $C f t r \Delta F / \Delta F$ nasal tissue compared to $C f t r+/+(w t)$ siblings. Responses are reported relative to $w t$ response (response ratio) to indicate the fold-increase in response. Error bars represent SEM, $n=4$ for each. Significance determined by $t$ test. ${ }^{*} p<0.001$. E) Representative traces of wt mice from the $\triangle F 508(\Delta F)$ and $\mathrm{R} 117 \mathrm{H}$ colonies. Mean response for wt mice in the $\triangle \mathrm{F}$ and $\mathrm{R} 117 \mathrm{H}$ colonies are $54.5+/-0.5 \mathrm{pC}$ and $55.7+/$ $1.5 \mathrm{pC}$, respectively.

Effect of CFTR correction on membrane cholesterol content The above data demonstrate that mutation of CFTR results in an increase in membrane cholesterol content. To verify if this effect is truly dependent on CFTR, membrane cholesterol accessibility in the CF epithelial cell line IB3 cells $(\Delta$ F508/W128X) and in S9 cells (IB3 cells stably expressing wt CFTR) was measured. The goal of this experiment is to determine if restoring wt CFTR expression in a CF cell will restore normal membrane cholesterol homeostasis. As shown in Figure 2, S9 cell membrane cholesterol content is significantly reduced compared to parent IB3 cells. These data support the

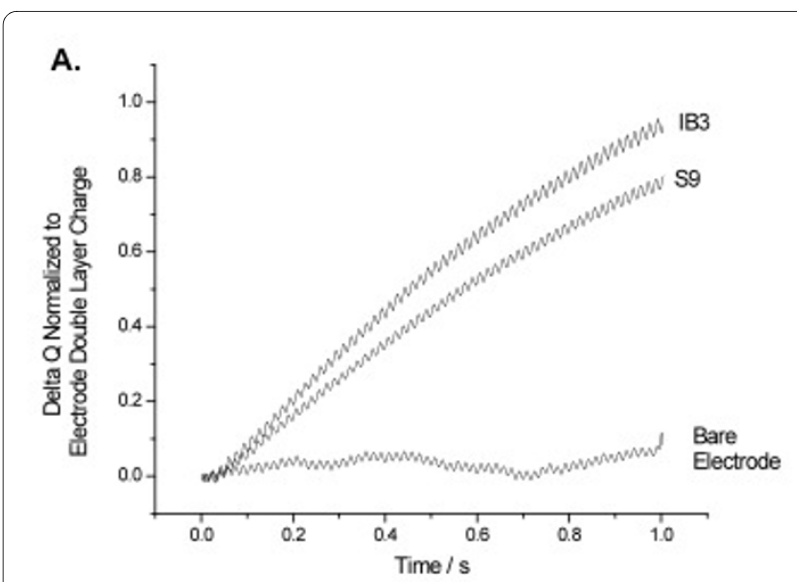

B.

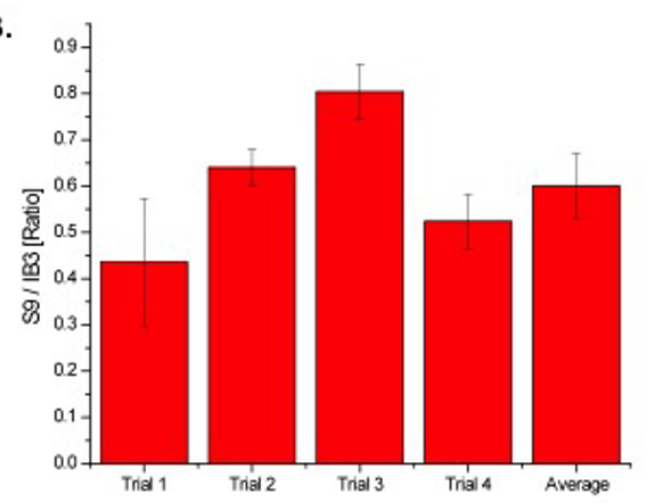

Figure 2 Electrochemical determination of membrane cholesterol content in CFTR corrected CF cells. A) Representative traces of membrane cholesterol determination in IB3 CF cells and in CFTR-corrected IB3 cells (S9). B) Quantification of responses between IB3 and S9 cells. Responses are reported relative to $w t$ response (response ratio) to indicate the fold-increase in response. Error bars represent SEM, $n=4$ for each. Significance determined by $t$ test. ${ }^{*} p<0.001$.

hypothesis that wt CFTR is required to maintain membrane cholesterol homeostasis.

\section{The effect of pharmacological inhibition of CFTR on membrane cholesterol content}

Data indicate a clear influence of CFTR genotype on membrane cholesterol content regulation. The mouse models and cell models used model chronic alterations to CFTR. The goal of this experiment is to determine the impact of acutely modulating CFTR with pharmacological inhibitors on membrane cholesterol. 9/HTEo-epithelial cells were treated with the CFTR selective inhibitor CFTR $_{\text {inh }}-172(20 \mu \mathrm{M})$ for $24 \mathrm{~h}$ and membrane cholesterol content measured electrochemically $[16,18]$. CFTR inhibition under these conditions with this compound has been reported to reproduce cell regulation profiles associated with CF inflammation [19]. Contrary to cellular 
A.

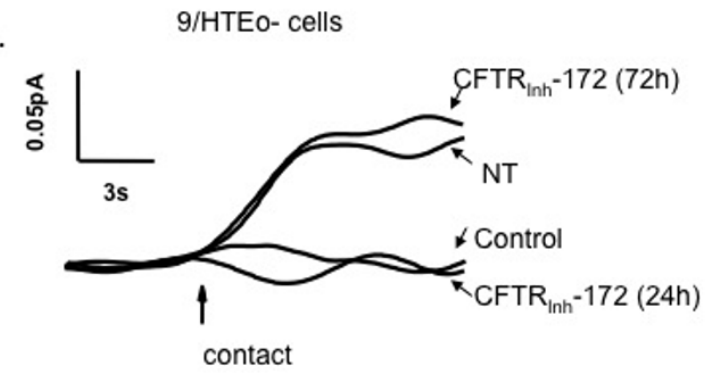

B.

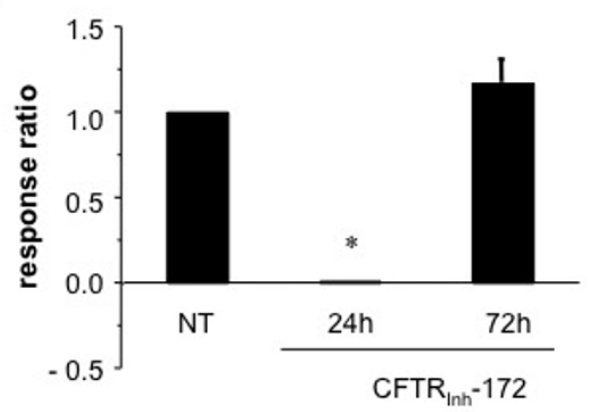

Figure 3 Effect of $24 \mathrm{~h}$ CFTR inhibition and $72 \mathrm{~h}$ CFTR inhibition with $\mathrm{CFTR}_{\text {inh }^{-172}}(20 \mu \mathrm{M})$ on membrane cholesterol content. A) Representative traces of membrane cholesterol determination in 9/ HTEo-cells after treatment with the CFTR inhibitor CFTR $_{\text {inh }}$-172 for either $24 \mathrm{~h}$ or $72 \mathrm{~h}$ with fresh inhibitor placed on cells every $24 \mathrm{~h}$ or cells with no treatment (NT). B) Quantification of responses between cells with no treatment (NT) and cells with acute (24 h) or chronic (72 h) CFTR inhibition. Responses are reported relative to NT response (response ratio) to indicate the fold difference in response. Error bars represent $S E M, n=4$ for each. Significance determined by ANOVA relative to NT samples. ${ }^{*} p<0.001$.

and in vivo CF models, acute CFTR inhibition resulted in a dramatic reduction in membrane cholesterol accessibility (Figure 3). This finding suggested that increased membrane cholesterol content in CF is actually a secondary response. To test this hypothesis, 9/HTEo-cells were exposed to CFTR $_{\text {inh }}-172(20 \mu \mathrm{M})$ continuously for $72 \mathrm{~h}$ being replenished with fresh drug every $24 \mathrm{~h}$. Longer CFTR inhibition results in a rebounding of membrane cholesterol that begins to exceed baseline levels, although not statistically significant at this time point (Figure 3). These data suggest that alterations in cholesterol processing in CF may be due to feedback mechanisms triggered by initially diminished membrane cholesterol content in response to lost CFTR function. However, membrane cholesterol does not significantly exceed baseline levels after $72 \mathrm{~h}$. Pharmacological inhibition of CFTR with $\mathrm{CFTR}_{\text {inh }}-172$ does not recapitulate the whole process of CF alterations in cholesterol processing and the source of increased membrane cholesterol content still needs to be determined.

To assure that CFTR $_{\text {inh }}-172$ was likely mediating the drop in membrane cholesterol via CFTR inhibition, two controls were performed. First, the influence of CFTR inh $^{-}$ 172 on CF-model pCEPR 9/HTEo-cells was examined. The pCEPR cells are lacking CFTR function due to the over expression of the regulatory $(R)$ domain and have been shown to exhibit the phenotype of increased membrane cholesterol content compared to wt controls $[3,11]$. If the initial drop in membrane cholesterol content is due to CFTR inhibition, CFTR inh $^{-172}$ should have no effect in pCEPR cells. Exposure of CF-model pCEPR cells to CFTR $_{\text {inh }}-172(20 \mu \mathrm{M})$ for $24 \mathrm{~h}$ indeed has no impact on membrane cholesterol content (Figure 4A, B). These data

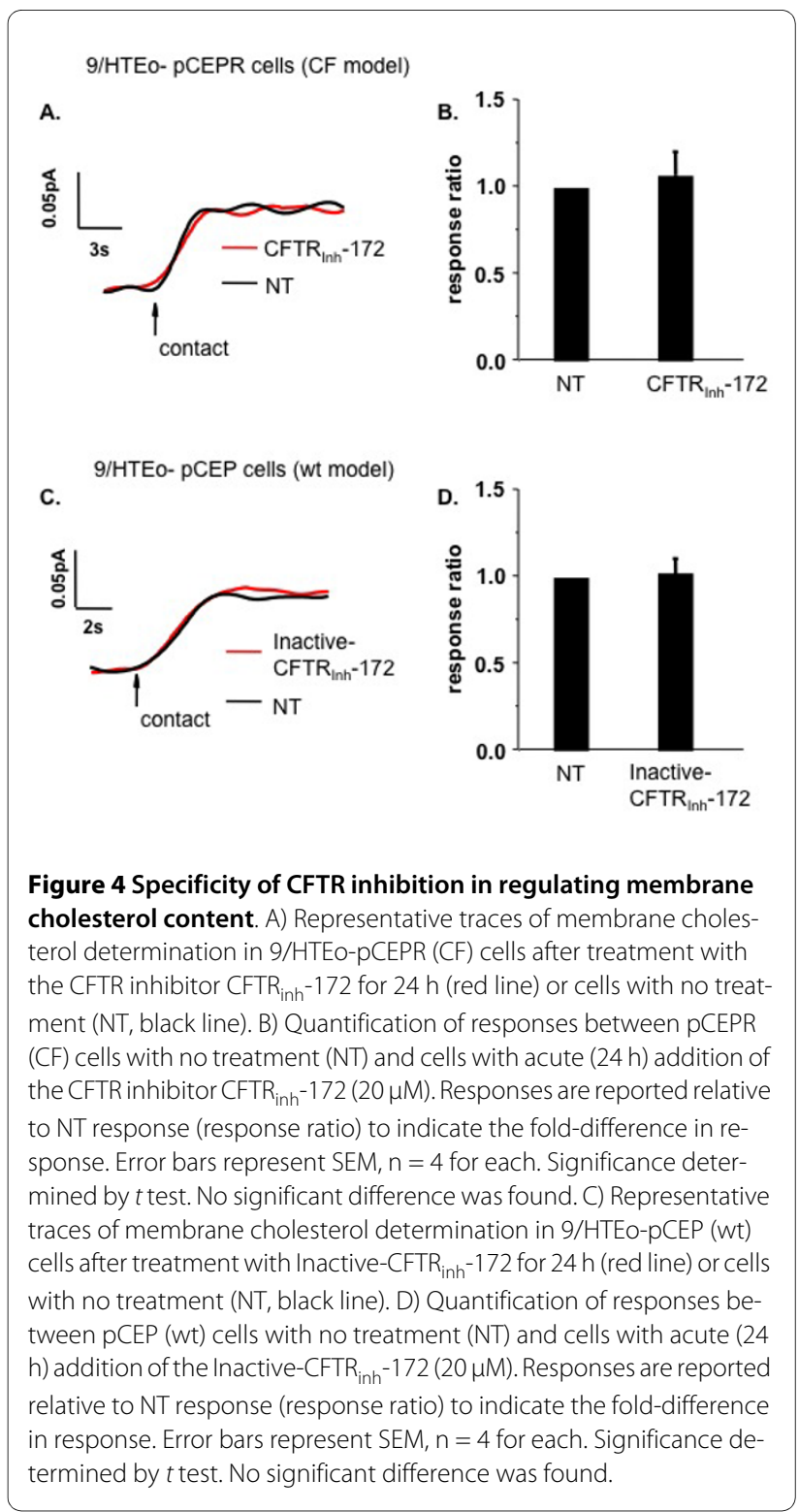


support the finding that the initial drop in membrane cholesterol is due to acute CFTR inhibition, and further suggest that the subsequent increase in membrane cholesterol content in CF cells is due to a secondary feedback response. A second control consisted of treating 9/HTEo-

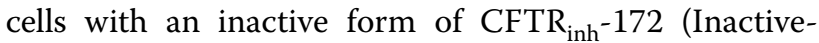
$\mathrm{CFTR}_{\text {inh }}$-172) to verify that some nonspecific drug interaction was not responsible for the decrease in membrane cholesterol. As shown in Figures 4C and 4D, Inactive$\mathrm{CFTR}_{\text {inh }}-172$ had no influence on membrane cholesterol content. These data strongly support the findings that acute inhibition of CFTR function leads to decreased membrane cholesterol content.

To confirm that inhibition of CFTR influences membrane cholesterol content, the effect of a second pharmacological inhibitor of CFTR, Gly H101 $(10 \mu \mathrm{M})$, was examined. A similar, but slightly modified, electrochemical technique was used to test the influence of Gly H101 on membrane cholesterol. A background subtraction analog chronocoulometry method is used to quantify hydrogen peroxide production, which correlates to cholesterol content. With the electrode held in contact with the cell surface, several measurements reflecting membrane cholesterol are collected. Consistent with CFTR inh $^{-}$ 172 results, cells treated with Gly $\mathrm{H} 101$ for $24 \mathrm{~h}$ demonstrate a significant decrease in cholesterol content that rebounds to baseline levels by $72 \mathrm{~h}$ (Figure 5).

\section{Heterozygote effect}

The finding that acute CFTR inhibition leads to significant membrane cholesterol depletion, coupled with the observations that both mild and severe CFTR mutations result in elevated membrane cholesterol content, prompted the examination of what the effect of CFTR heterozygosity woud be on membrane cholesterol accessibility. The goal of the study was to determine if there is a CFTR dose effect with Cftr +/- mice having elevated membrane cholesterol intermediated between wt and CF models, or if there was actually a loss of membrane cholesterol as seen with acute CFTR inhibition. As shown in Figure 6, Cftr + /- nasal epithelium exhibits a relatively slight, but significant loss of membrane cholesterol $(0.87$ $+/$ - 0.04 fold compared to wt, $\mathrm{p}<0.01$ ). These data suggest that CFTR heterozygosity impacts cholesterol movement to the plasma membrane. These data can be consistent with the pharmacological inhibition of CFTR data in that CFTR may be involved in cholesterol movement to the membrane and reduced membrane cholesterol triggers a feedback response. The slight drop in membrane cholesterol content in Cftr +/- nasal tissue, although statistically significant, is likely physiologically insufficient to trigger a compensatory mechanism to increase cholesterol synthesis.
A.

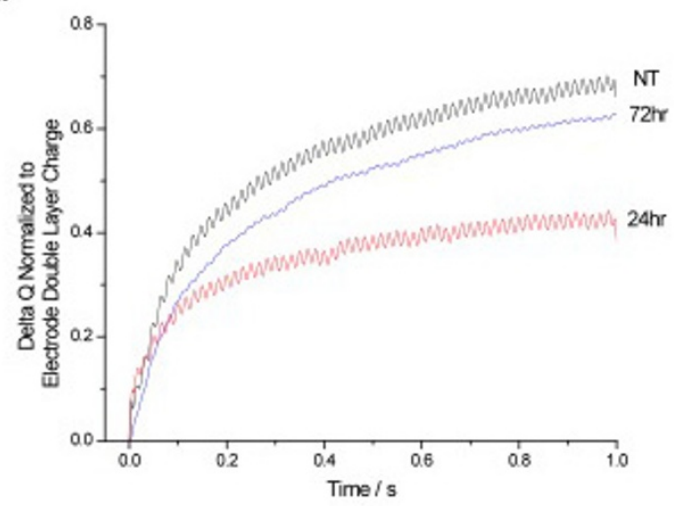

B.

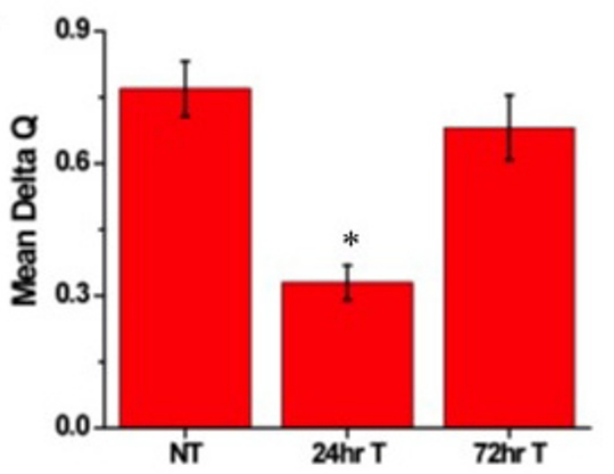

Figure 5 Effect of $24 \mathrm{~h}$ CFTR inhibition and $72 \mathrm{~h}$ CFTR inhibition with Gly H101 (20 $\mu \mathrm{M})$ on membrane cholesterol content. A) Representative traces of membrane cholesterol determination in 9/HTEOcells after treatment with the CFTR inhibitor Gly H101 for either $24 \mathrm{~h}$ or $72 \mathrm{~h}$ with fresh inhibitor placed on cells every $24 \mathrm{~h}$ or cells with no treatment (NT). B) Quantification of responses between cells with no treatment (NT) and cells with acute (24 h) or chronic (72 h) CFTR inhibition. Responses are reported relative to NT response (response ratio) to indicate the fold-difference in response. Error bars represent SEM, $n$ $=4$ for each. Significance determined by ANOVA relative to NT samples. ${ }^{*} p<0.001$

Increased lung cholesterol synthesis in two different mouse models of CF

Lange and Steck described a relationship between membrane cholesterol content and the regulation of cholesterol synthesis [20]. A potential mechanism for the rebound of membrane cholesterol observed with pharmacological CFTR inhibitors would be an increase in de novo synthesis in response to transient decreases in membrane cholesterol content in response to dysfunctional CFTR. A prediction based on this mechanism would be that cholesterol synthesis should correlate with CFTR genotype in relation to membrane cholesterol con- 
A.

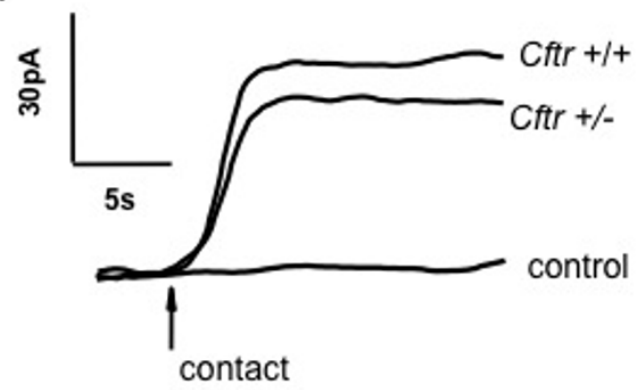

B.

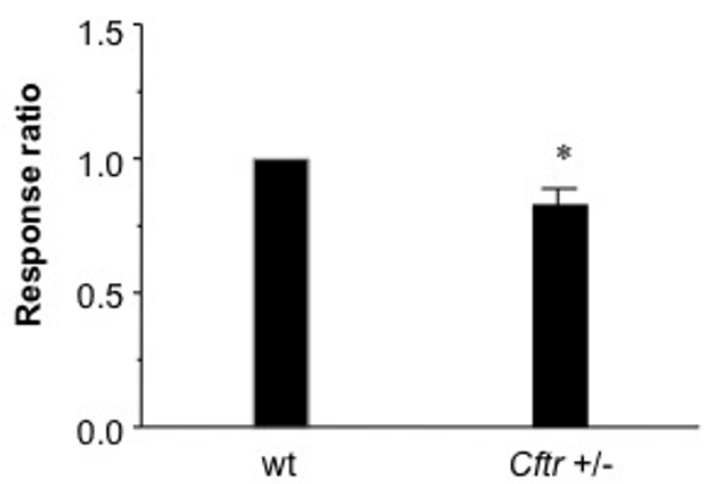

Figure 6 Comparison of nasal epithelium membrane cholesterol content in Cftr +/+ and Cftr +/- mice. A) Representative traces of membrane cholesterol determination in excised nasal epithelium from $\mathrm{Cftr}+/+$ (wt) mice and Cftr +/- mice. B) Quantification of electrochemical membrane cholesterol determination between $\mathrm{Ctt}+/+(\mathrm{wt})$ nasal tissue and Cftr +/- nasal tissue. Responses are reported relative to wt response (response ratio) to indicate the fold-difference in response. Error bars represent SEM, $n=4$ for each. Significance determined by $t$ test. ${ }^{*} p=0.008$.

tent in the airways. To test this prediction, lung de novo cholesterol synthesis in $\Delta \mathrm{F} / \Delta \mathrm{F}$ and $\mathrm{R} / \mathrm{R}$ mice was measured. Deuterium incorporation into cholesterol of specific tissue was determined by GC/MS analysis. Results reveal a $1.6 \pm 0.2$ fold $(\mathrm{p}=0.009)$ increase in \% new cholesterol synthesis in the lung of $\Delta \mathrm{F} / \Delta \mathrm{F}$ mouse lung compared to controls and a $1.2 \pm 0.1$ fold $(\mathrm{p}=0.04)$ in the lungs of $\mathrm{R} / \mathrm{R}$ mice compared to respective controls (Figure 7A). Increased cholesterol synthesis in the lungs of two other CF mouse models validates our previous findings in Cftr-/- mouse tissue [3], and a more severe CFTR mutation correlates with greater increases in the rate of cholesterol synthesis in the lung, supporting the importance of CFTR function in influencing cholesterol synthesis.
A.

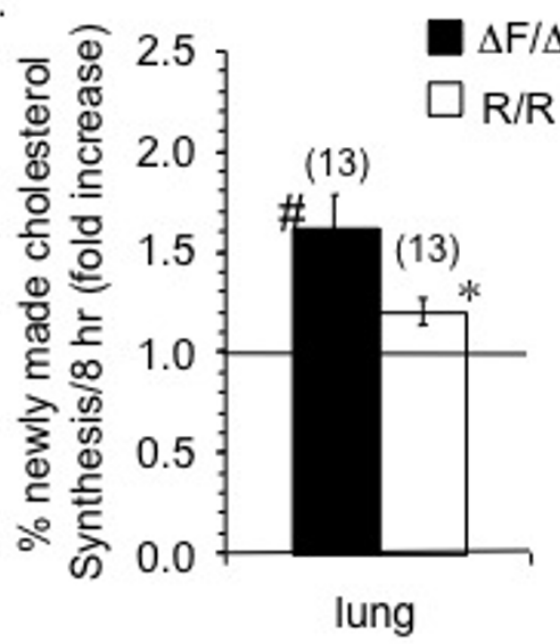

B.

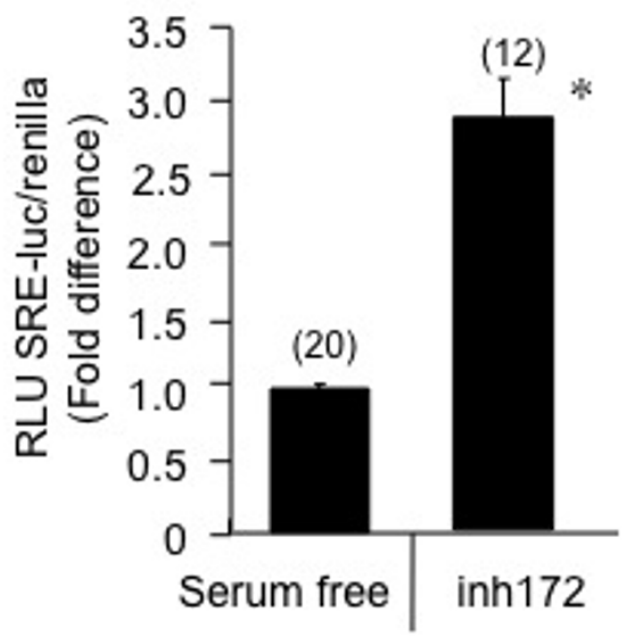

Figure 7 De novo cholesterol synthesis in CF mouse lung compared to matched controls. A) Deuterium incorporation into newly synthesized tissue cholesterol was measured by GC/MS. Data is normalized to each tissue wt control (represented by dotted line) and reported as fold increase of $\%$ newly synthesized cholesterol $/ 8 \mathrm{~h}$. Filled bars represent $\Delta F / \Delta F$ mice and open bars represent $R / R$ mice. The number of replicates is shown in parenthesis above each bar and represents individual assay on multiple tissue samples obtained over 3 experiments. ${ }^{*} p<0.05$, \#p $<0.01$. B) Increased SRE response in CFTR inh $^{-}$ 172 treated control epithelial cells. 9/HTEo-pCEP (wt) cells were incubated in serum free conditions for $24 \mathrm{~h}$ with or without $20 \mathrm{\mu M} \mathrm{CFTR}_{\text {inh }}{ }^{-}$ 172 (INH-172) in serum free media for an additional $24 \mathrm{~h}$. 9/HTEO-pCEP are open bars. Data are normalized to serum free NT control levels over 3 experiments. Number ( $n$ ) of samples is in parenthesis above each bar. Significance was determined by $t$ test. Error bars represent SEM. ${ }^{*} \mathrm{p}<$ 0.0001 . 


\section{Increased sterol response element (SRE) activation in response to CFTR inhibition}

The above data suggest that CFTR genotype influences the regulation of de novo cholesterol regulation. Based on the above results it is predicted that treatment with CFTR inhibitors should result in SRE activation. To test this prediction, the effect of the CFTR inhibitor CFTR inh -172 on SRE activation was examined utilizing an SRE-luciferase construct. The construct contains SRE binding sites of the promoter region of HMG-CoA synthase, the ratelimiting enzyme regulating de novo cholesterol synthesis. 9/HTEo-cells were treated with 20!M CFTR inh -172 for 24 hours and assayed for SRE responsiveness. Control epithelial cells treated with $\mathrm{CFTR}_{\text {inh }}-172$ showed a significant increase of $2.8+0.3$ fold $(\mathrm{p}<0.0001)$ above control levels (Figure 7B). These data are consistent with the in vivo data above that loss of CFTR function leads to an increase in de novo cholesterol synthesis.

\section{Regulation of membrane cholesterol content by cholesterol synthesis in CF}

The above data suggest a relationship between cholesterol synthesis and membrane cholesterol content. To test directly whether cholesterol synthesis impacts membrane cholesterol content in CF cells and tissues, cholesterol synthesis was inhibited with two unrelated compounds, mevastatin and resveratrol, and the impact on membrane cholesterol content examined. Only CF cells were tested due to increased cholesterol signal at the membrane with electrochemical detection. It is anticipated that the relationship between cholesterol synthesis and membrane cholesterol accessibility would be the same in wt cells, but this relationship was not tested directly. Resveratrol was used because it is unrelated to the statin compounds and Do et al have shown that resveratrol reduces cholesterol synthesis in vivo in apo Edeficient mice through an AMP kinase (AMPK)-dependent mechanism [21]. In order to test the hypothesis that cholesterol synthesis contributes to membrane cholesterol content in CF cells, the impact of mevastatin and resveratrol on membrane cholesterol was examined. CF model 9/HTEo-pCEPR cells were chosen since they are cultured cells that exhibit the increased membrane cholesterol that is observed in vivo in mouse models of $\mathrm{CF}$ [6]. Cells were treated with either mevastatin $(50 \mu \mathrm{M})$ or resveratrol $(50 \mu \mathrm{M})$ for 24 hours. Resveratrol treated CF epithelial cell membrane cholesterol content is significantly decreased $(0.06 \mathrm{pA}+/-0.01$, $\mathrm{p}$-value $<0.001)$ compared to untreated cells (Figure 8A, B). The control trace represents a measurement taken with a bare electrode not modified with cholesterol oxidase to confirm the cholesterol sensitivity of the measurement. CF-model epithelial cells treated with mevastatin show a decrease in plasma membrane cholesterol content similar to what is

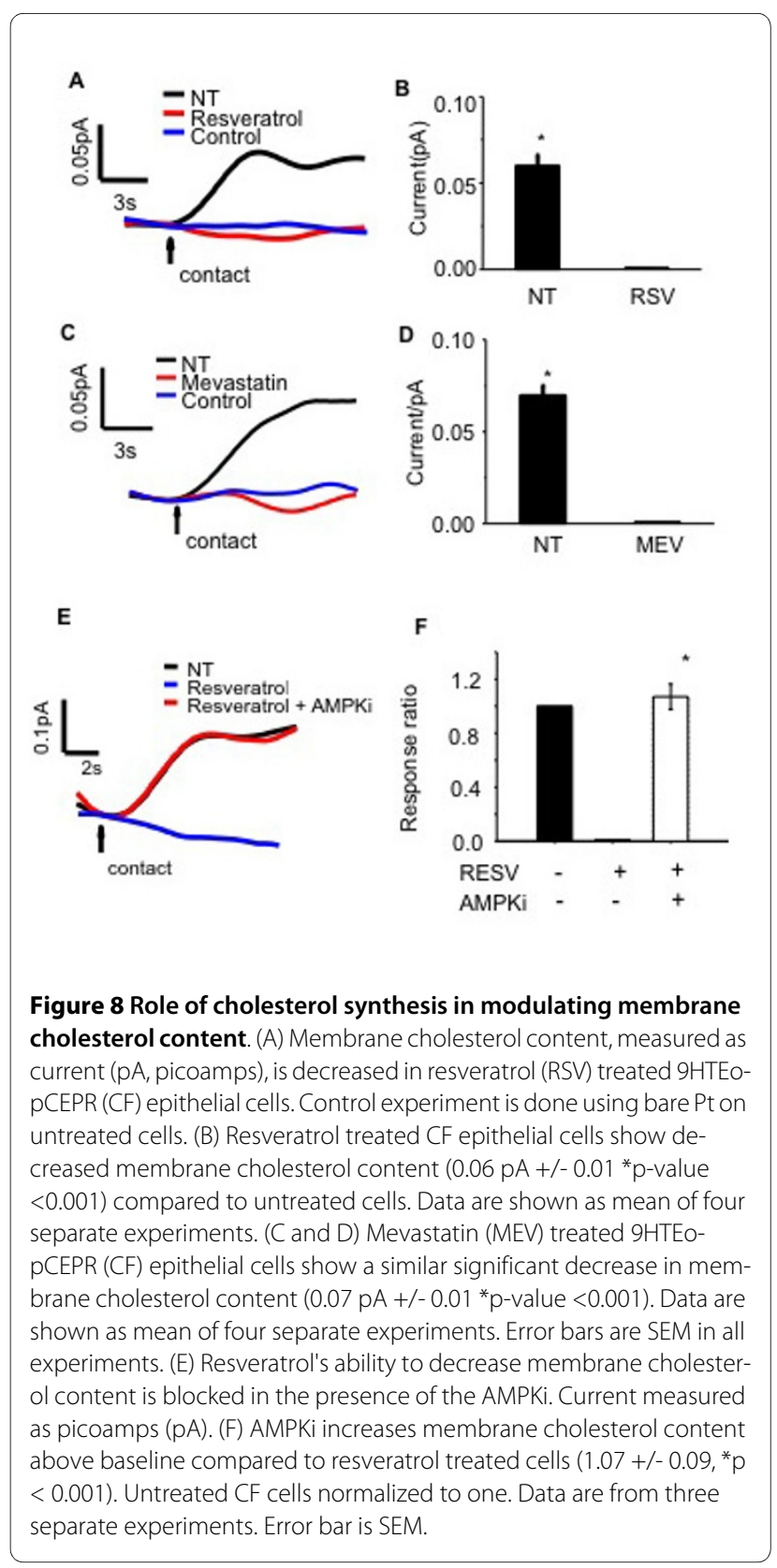

seen with resveratrol treatment $(0.07 \mathrm{pA}+/-0.01$, p-value $<0.001$ ) (Figure $8 \mathrm{C}, \mathrm{D}$ ). In the presence of AMPK inhibition (AMPKi compound $\mathrm{C}, 10 \mu \mathrm{m}$ for $24 \mathrm{~h}$ ), the resveratrol-mediated drop in membrane cholesterol is blocked $(1.07+/-0.09$ fold over RSV treated 9/HTEo- pCEPR (CF) epithelial cells, p-value <0.001) (Figure 8E, F).

\section{In vivo modulation of membrane cholesterol content by} resveratrol in CF mice

The cell lines used for the studies above were chosen since they are known to exhibit CF-related alterations to cholesterol accumulation and membrane cholesterol [6]. However, they are a clonal cell line that may not com- 
pletely reflect physiological responses. To determine whether the same intervention would have a similar impact on membrane cholesterol in a more physiologically relevant model, CFTR deficient (CFTR ${ }^{\text {tm } 14 n c)}$ mice and wt controls were treated with resveratrol for 3-6 weeks. Resveratrol was placed in the drinking water as previously described [21] and the average amount of resveratrol consumed was $15-28 \mathrm{mg} / \mathrm{kg} /$ day per mouse. The drug was tolerated well by all treatment groups. Resveratrol was chosen over mevastatin for ease of administration over an extended period of time and since it has been shown to be effective in vivo in mice previously [21]. All mice had adequate weight gain and lived until the time of sacrifice. After sacrifice, membrane cholesterol accessibility was determined from excised nasal epithelial in wt and CFTR ${ }^{t m 1 U n c}$ mice $(C f t r-/-)$ in the presence and absence of resveratrol. CF mice exhibited a decrease in membrane cholesterol detection in response to resveratrol compared to sibling untreated mice (Figure 9) (CF treated: $2.08+/-0.05 \mathrm{nC} \mathrm{v}$. CF control: $1.56+/-0.03 \mathrm{nC}$ ), $\mathrm{p}$-value $0.05, \mathrm{n}=3$ ). Membrane cholesterol detection also decreased in wt mice treated with resveratrol (wt treated:
A.

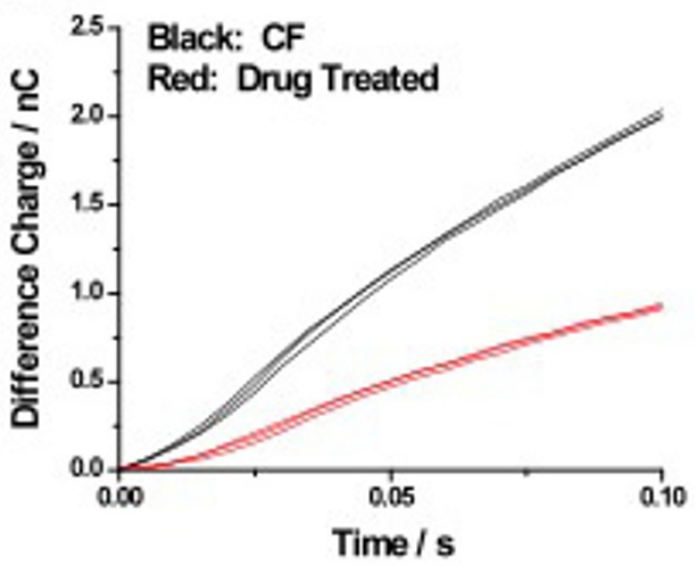

B.

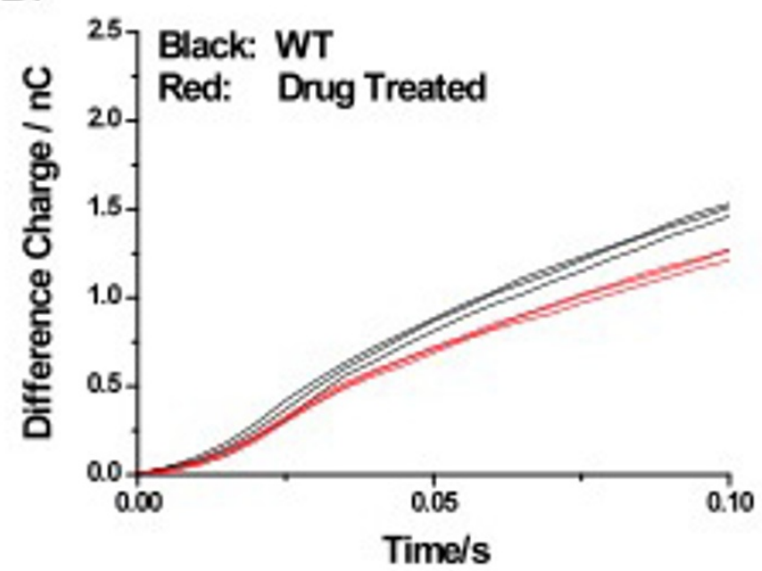

C.

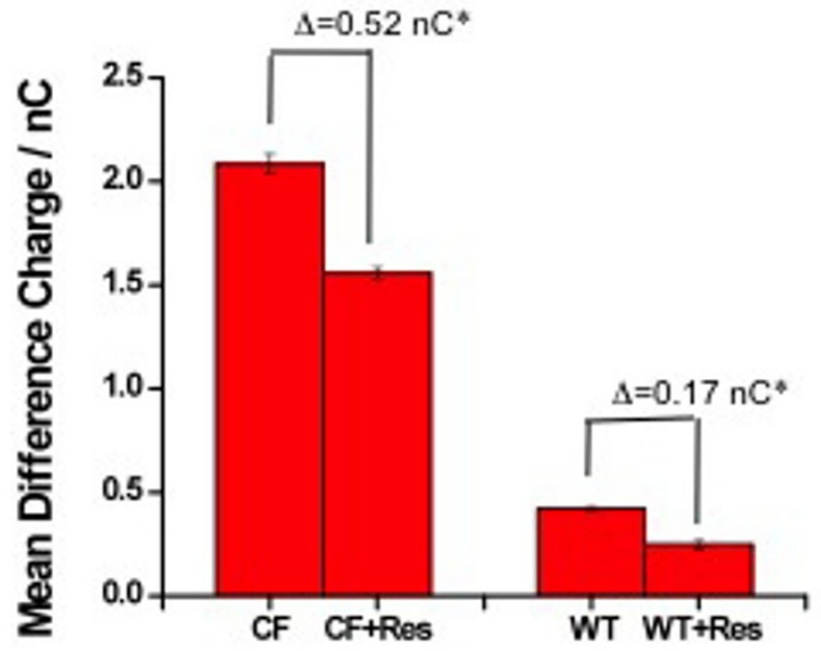

Figure 9 In vivo modulation of cholesterol in CF and wt mice with resveratrol. Membrane cholesterol measurement in Cftr -/- mouse (A) nasal epithelium and in Cftr+/+ mouse (B) nasal epithelium in response to in vivo exposure to resveratrol (drug treated, RES) (15-28 mg/kg body weight) for 3 to 6 weeks. Representative tracings of electrochemical detection of membrane cholesterol are shown. Shown are three separate tracings (separate electrodes) from tissue from a single mouse. C) Tissues from three treated and three untreated (ftr -/- mice were examined by eight separate electrodes and means represented in bar graph. Tissues from three treated and three untreated $\mathrm{Cftr}+/+$ mice were examined by six separate electrodes and means represented in bar graph *Significance determined from $n=3, p$-value $<0.05$ as determined by $t$-test. 
$0.25+/-0.02 \mathrm{nC}$ v. wt control: $0.42+/-0.01 \mathrm{nC}$ ), p-value $0.05, \mathrm{n}=3)$. The magnitude of response to resveratrol in CF mice $(0.52 \mathrm{nC})$ is greater than observed in wt $(0.17$ $\mathrm{nC})$, likely due to the increased signal in CF tissues and increased cholesterol synthesis. These data support the above cellular studies and demonstrate that cholesterol homeostasis is responsive to resveratrol in vivo and that electrochemical detection of membrane cholesterol is capable of monitoring responses.

A.

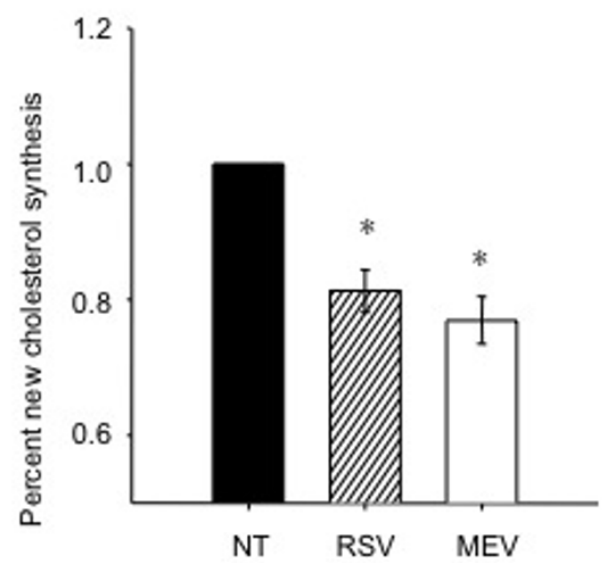

B.

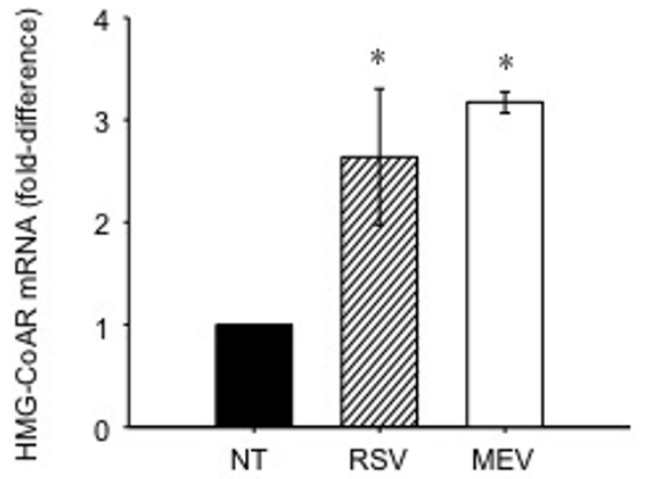

Figure 10 Cholesterol synthesis and HMG-CoAR mRNA expression in CF epithelial cells. (A) Cholesterol synthesis decreases by $20 \%$ in resveratrol treated 9HTEO-pCEPR (CF-model) epithelial cells compared to vehicle (DMSO) treated cells $(0.8+/-0.03$ fold below untreated cells ${ }^{*} p$-value $\left.<0.01\right)$. Mevastatin treated CF epithelial cells show a similar decrease in cholesterol synthesis compared to vehicle treated CF epithelial cells $\left(0.78+/-0.05,{ }^{*} p\right.$-value 0.04$)$. Data are the mean of three separate experiments. (B) HMG-CoAR mRNA expression in resveratrol (RSV) treated 9HTEo-pCEPR CF-model epithelial cells. An increase in HMG-COAR mRNA levels is seen with resveratrol $(50 \mu \mathrm{m}, 24 \mathrm{~h})$ treatment ( $2.6+/-0.6$ fold over untreated cells, ${ }^{*}$-value 0.03$)$. Mevastatin (MEV) used as a positive control shows a similar increase in HMGCoAR expression (3.172+/- 0.1 fold over untreated cells, ${ }^{*} p$-value 0.04$)$. Data are the mean of three separate experiments. Error bars are SEM. Mann-Whitney rank sum test used where normality test failed.

\section{Cholesterol synthesis}

To verify that mevastatin and resveratrol do inhibit cholesterol synthesis, cholesterol synthesis was measured in CF-model 9/HTEo-pCEPR epithelial cells by deuterium labelling. Resveratrol treated CF cells exhibit a 20 percent decrease in cholesterol synthesis compared to vehicle treated cells $(0.80+/-0.03$ fold below untreated cells, $\mathrm{p}$ value 0.005$)$. Mevastatin, as a positive control, demonstrates a similar decrease in cholesterol synthesis in CF epithelial cells (Figure 10A).

\section{HMG-CoAR expression in resveratrol treated CF epithelial cells}

To further verify the direct measures of cholesterol synthesis above, an indirect measure of biochemical response to reduced cholesterol synthesis was examined. A response to decreased cholesterol synthesis is up-regulation of the sterol response element (SRE) pathway to increase the expression of synthesis enzymes such as HMG-CoAR. HMG-CoAR mRNA levels were examined by $\mathrm{RT}-\mathrm{PCR}$ in response to resveratrol in CF model 9HTEo-pCEPR epithelial cells. A 2.6 fold increase in HMG-CoAR mRNA levels is seen in resveratrol treated CF cells $(2.6+/-0.6$ fold over untreated cells, p-value 0.025 ) compared to untreated CF cells (Figure 10B). This finding is consistent with findings of cholesterol synthesis inhibition by resveratrol. A similar increase in HMGCoAR expression is seen in mevastatin treated cells as a positive control. These results support the findings that resveratrol inhibits cholesterol synthesis

\section{Discussion}

Membrane cholesterol is capable of modulating a variety of cellular functions including the regulation of ion channels such as $\mathrm{ENaC}$ and the formation of signaling complexes [22]. In addition to intracellular perinuclear accumulation of free cholesterol, our previous work has identified a CF-related increase in membrane cholesterol accessible to electrochemical detection and in increase in de novo cholesterol synthesis [3]. Excess cholesterol can be stored in membrane fractions and initially it was thought that excess membrane cholesterol in CF cells was the result of passive diffusion of excess cholesterol to the membrane. Given the potential importance of chronic alterations in membrane cholesterol and de novo synthesis, the goal of this manuscript is to determine if CFTR genotype influences these outcome measures. Regardless if cholesterol-processing alterations prove to be critical to CF pathogenesis, cholesterol measurements could prove to be important biomarkers for CF-related cellular processes that are important to pathogenesis.

Presented data demonstrate that membrane cholesterol is responsive to CFTR genotype. $R / R$ mice exhibit a 1.6fold increase in membrane cholesterol content in nasal 
epithelium compared to sibling wt mice, whereas, $\Delta \mathrm{F} / \Delta \mathrm{F}$ mice exhibit a 2.1-fold increase. Interestingly, acute $24 \mathrm{~h}$ CFTR inhibition with either CFTR $_{\text {inh }}-172$ or Gly H101 results in a decrease in membrane cholesterol content. However, $72 \mathrm{~h}$ exposure to either CFTR inhibitor (replenished every $24 \mathrm{~h}$ ) results in a rebound in cholesterol content suggesting a secondary cellular response to lost CFTR function is influencing membrane cholesterol regulation. The rebound effect does not lead to elevated membrane cholesterol as seen in CF cells and tissues [3], indicating that the conditions tested here are not completely replicating the CF situation. The lack of excess cholesterol in response to acute CFTR inhibition is unexplained. One possible explanation for observed results is that $72 \mathrm{~h}$ pharmacological inhibition of CFTR does not lead to sufficient free cholesterol accumulation to be distributed to the plasma membrane.

Mechanistically, de novo cholesterol synthesis is at least a contributing factor to membrane cholesterol. Direct measurement of cholesterol synthesis reveals that lungs from $\mathrm{R} / \mathrm{R}$ mice make significantly less cholesterol than $\Delta \mathrm{F} / \Delta \mathrm{F}$ mouse lungs, although cholesterol synthesis in both genotypes is elevated compared to respective wt controls. This ratio is consistent with relative changes in membrane cholesterol content. Also, two inhibitors of cholesterol synthesis, mevastatin and resveratrol, reduce membrane cholesterol content in CF cells. In vivo treatment with resveratrol also reduces nasal membrane cholesterol in Cftr-/- mice.

The increased cholesterol synthesis we have observed in CF cells and tissues is a likely contributor to increased membrane cholesterol content in CF, but not likely the sole contributor. The model proposed by Lange and Steck [20] fits the rebound effect we see with the two CFTR inhibitors. This model also fits our data as to why the $72 \mathrm{~h}$ cholesterol content does not exceed baseline levels as increased synthesis would be expected to only normalize membrane content according the to the Lange and Steck model. If cholesterol synthesis in response to impeded cholesterol transport to the plasma membrane is insufficient to drive the excess plasma membrane cholesterol seen in CF, then what is responsible? As a model we propose that mutations in CFTR disrupt cholesterol movement to the plasma membrane likely through disruption of endosomal trafficking, either directly or indirectly, which is consistent with cholesterol accumulation reported in CF cells [1-4]. This disruption leads to a chronic increase in de novo cholesterol synthesis as predicted by the Lange and Steck model. Finally, as free cholesterol accumulates in endosomes/lysosomes of CF cells, excess cholesterol is stored in the plasma membrane leading to excess plasma membrane cholesterol observed in CF cells and tissues. This excess storage is likely not achieved in $72 \mathrm{~h}$ CFTR inhibitor treatment accounting for the lack of CF-like membrane cholesterol increases.

\section{Conclusions}

The conclusion of this study is that the measurement of membrane cholesterol accessibility to electrochemical detection is influenced by CFTR. CFTR genotype correlations with the measurement, reversion to wt levels in CF cells with the introduction of wt CFTR, and pharmacological manipulation of CFTR with two separate inhibitors influencing membrane cholesterol all point to a key role of CFTR in modulating this phenotype. It is also concluded that de novo cholesterol synthesis contributes significantly to the regulation of membrane cholesterol. The initiating step in CF-related alterations of cholesterol homeostasis appears to be loss of a CFTR-mediated movement of cholesterol to the plasma membrane followed by a subsequent increase in de novo cholesterol synthesis. The mechanism by which CFTR influences movement of cholesterol to the plasma membrane is unknown and under investigation. A candidate mechanism being explored is CFTR function may influence endosomal trafficking. Multiple reports demonstrate CFTR presence in the endocytic pathway, but any relationship to lipid trafficking is speculative [23-25]. Our previous data suggest that a localized increase in cAMP signaling is a strong candidate as a regulator of this system in CF [1]. Also unknown is the driving force for the ultimate increase in membrane cholesterol accessibility. One possibility is an increase in cholesterol efflux. We have measured total cholesterol in $C f t r \Delta F / \Delta F$ mouse livers and in the CF-model 9/HTEo-pCEPR cells and neither exhibits a significant increase in total cholesterol compared to respective controls (not shown). These data may indicate that CF cells have elevated cholesterol efflux that could potentially be represented in the electrochemical detection data as discussed above. Our previous work has demonstrated an increase of expression of the cholesterol transport protein NPC1 in CF cells [4]. One of the roles of NPC1 is the transport of cholesterol to the plasma membrane from endosomes [26]. The role of increased NPC1 expression in CF cells perhaps in response to cholesterol accumulation is also being explored as a potential mechanism leading to increased cholesterol accessibility at the plasma membrane.

\footnotetext{
Competing interests

The authors declare that they have no competing interests.
}

\section{Authors' contributions}

DF, MM, RW, and DJ all contributed to electrochemical measurements of cholesterol dividing work between different CFTR inhibitors, mevastatin and resveratrol treatments, and cell and nasal tissue studies. JB designed all electrochemical measurement studies and interpreted those data. NS provided CFTR inhibitors and aided in designing those studies. JR performed studies with resveratrol and mevastatin. TK designed the study in whole, interpreted data, and wrote the manuscript. 


\section{Acknowledgements}

This work is supported by a grant from the Cystic Fibrosis Foundation and by $\mathrm{NIH/NHLBI}$ grant HL080319. Technical support for this project was provided by core facilities of the cystic fibrosis center (P30 DK 27651). The authors thank Dr. Pam Davis (CWRU) for providing cell lines necessary for the completion of this study and to Nicole White and P. Bead for technical assistance.

\section{Author Details}

1Department of Chemistry, Case Western Reserve University, Cleveland, $\mathrm{OH}$ 44106, USA, 2Department of Pediatrics and Pharmacology, Case Western Reserve University, Cleveland, OH 44106, USA, ${ }^{3}$ Department of Nutrition, Case Western Reserve University, Cleveland, OH 44106, USA and ${ }^{4}$ Department of Medicine, University of California, San Francisco, CA 94143, USA

Received: 4 January 2010 Accepted: 20 May 2010

Published: 20 May 2010

\section{References}

1. Manson ME, Corey DA, White NM, Kelley TJ: CAMP-mediated regulation of cholesterol accumulation in cystic fibrosis and Niemann-Pick type C cells. Am J Physiol Lung Cell Mol Physiol 2008, 295:L809-819.

2. Gentzsch M, Choudhury A, Chang XB, Pagano RE, Riordan JR: Misassembled mutant DeltaF508 CFTR in the distal secretory pathway alters cellular lipid trafficking. J Cell Sci 2007, 120:447-55.

3. White NM, Jiang D, Burgess JD, Bederman IR, Previs SF, Kelley TJ: Altered cholesterol homeostasis in cultured and in vivo models of cystic fibrosis. Am J Physiol Lung Cell Mol Physiol 2007, 292:L476-486.

4. White NM, Corey DA, Kelley TJ: Mechanistic similarities between cultured cell models of cystic fibrosis and niemann-pick type C. Am J Respir Cell Mol Biol 2004, 31:538-543.

5. Hyde SC, Emsley P, Hartshorn MJ, Mimmack MM, Gileadi U, Pearce SR, Gallagher MP, Gill DR, Hubbard RE, Higgins CF: Structural model of ATPbinding proteins associated with cystic fibrosis, multidrug resistance and bacterial transport. Nature 1990, 346:362-365.

6. Riordan JR, Rommens JM, Kerem B, Alon N, Rozmahel R, Grzelczak Z, Zielenski J, Lok S, Plavsic N, Chou JL: Identification of the cystic fibrosis gene: cloning and characterization of complementary DNA. Science 1999, 245:1066-1073.

7. Oram JF, Vaughan AM: ABCA1-mediated transport of cellular cholesterol and phospholipids to HDL apolipoproteins. Curr Opin Lipido/ 2000, 11:253-260.

8. Christiansen-Weber TA, Voland JR, Wu Y, Ngo K, Roland BL, Nguyen S, Peterson PA, Fung-Leung WP: Functional loss of ABCA1 in mice causes severe placental malformation, aberrant lipid distribution, and kidney glomerulonephritis as well as highdensity lipoprotein cholesterol deficiency. Am J Pathol 2000, 157:1017-1029.

9. Koter M, Broncel M, Chojnowska-Jezierska J, Klikczynska K, Franiak I: The effect of atorvastatin on erythrocyte membranes and serum lipids in patients with type-2 hypercholesterolemia. Eur J Clin Pharmacol 2002. 58:501-506.

10. Uyuklu M, Meiselman HJ, Baskurt OK: Effect of decreased plasma cholesterol by atorvastatin treatment on erythrocyte mechanical properties. Clin Hemorheol Microcirc 2007, 36:25-33.

11. Perez A, Risma KA, Eckman EA, Davis PB: Overexpression of R domain eliminates CAMP-stimulated $\mathrm{Cl}$-secretion in 9/HTEo-cells in culture. Am J Physiol 1996, 271:L85-92.

12. Zeiher BG, Eichwald E, Zabner J, Smith JJ, Puga AP, McCray PB Jr, Capecchi MR, Welsh MJ, Thomas KR: A mouse model for the delta F508 allele of cystic fibrosis. J Clin Invest 1995, 96:2051-2064.

13. van Heeckeren AM, Schluchter MD, Drumm ML, Davis PB: Role of Cftr genotype in the response to chronic Pseudomonas aeruginosa lung infection in mice. Am J Physiol Lung Cell Mol Physiol 2004, 287:L944-952.

14. Devadoss A, Palencsar MS, Jiang D, Honkonen ML, Burgess JD: Enzyme modification of platinum microelectrodes for detection of cholesterol in vesicle lipid bilayer membranes. Anal Chem 2005, 77:7393-7398

15. Jiang D, Devadoss A, Palencsár MS, Fang D, White NM, Kelley TJ, Smith JD, Burgess JD: Direct electrochemical evaluation of plasma membrane cholesterol in live mammalian cells. J Am Chem Soc 2007, 129:11352-11353
16. Sonawane ND, Muanprasat C, Nagatani R Jr, Song Y, Verkman AS: In vivo pharmacology and antidiarrheal efficacy of a thiazolidinone CFTR inhibitor in rodents. J Pharm Sci 2005, 94:134-143.

17. Jiang D, Fang D, Kelley TJ, Burgess JD: Electrochemical analysis of cell plasma membrane cholesterol at the airway surface of mouse trachea. Anal Chem 2008, 80:1235-1239.

18. Ma T, Thiagarajah JR, Yang H, Sonawane ND, Folli C, Galietta LJ, Verkman AS: Thiazolidinone CFTR inhibitor identified by high-throughput screening blocks cholera toxin-induced intestinal fluid secretion. J Clin Invest 2002, 110:1651-1658.

19. Perez A, Issler AC, Cotton CU, Kelley TJ, Verkman AS, Davis PB: CFTR inhibition mimics the cystic fibrosis inflammatory profile. Am J Physiol Lung Cell Mol Physiol 2007, 292:L383-395.

20. Lange $Y$, Ye J, Steck TL: How cholesterol homeostasis is regulated by plasma membrane cholesterol in excess of phospholipids. Proc Nat Acad SciUSA 2004, 101:11664-11667.

21. Do GM, Kwon EY, Kim HJ, Jeon SM, Ha TY, Park T, Choi MS: Long-term effects of resveratrol supplementation on suppression of atherogenic lesion formation and cholesterol synthesis in apo E-deficient mice. Biochem Biophys Res Commun 2008, 374:55-59.

22. Balut C, Steels P, Radu M, Ameloot M, Driessche WV, Jans D: Membrane cholesterol extraction decreases $\mathrm{Na}+$ transport in $\mathrm{A} 6$ renal epithelia. Am J Physiol Cell Physiol 2006, 290:C87-94

23. Cholon DM, O'Neal WK, Randell SH, Riordan JR, Gentzsch M: Modulation of endocytic trafficking and apical stability of CFTR in primary human airway epithelial cultures. Am J Physiol Lung Cell Mol Physiol 2010, 298:L304-L314

24. Gentzsch M, Chang XB, Cui L, Wu Y, Ozols VV, Choudhury A, Pagano RE, Riordan JR: Endocytic trafficking routes of wild type and DeltaF508 cystic fibrosis transmembrane conductance regulator. Mol Biol Cell 2004, 15:2684-2696.

25. Swiatecka-Urban A, Brown A, Moreau-Marquis S, Renuka J, Coutermarsh B, Barnaby R, Karlson KH, Flotte TR, Fukuda M, Langford GM, Stanton BA: The short apical membrane half-life of rescued \{Delta\}F508-cystic fibrosis transmembrane conductance regulator (CFTR) results from accelerated endocytosis of $\{$ Delta\}F508-CFTR in polarized human airway epithelial cells. J Biol Chem 2005, 280:36762-36772

26. Wojtanik KM, Liscum L: The transport of low density lipoprotein-derived cholesterol to the plasma membrane is defective in NPC1 cells. J Biol Chem 2003, 278:14850-14856.

doi: 10.1186/1465-9921-11-61

Cite this article as: Fang et al., Increased plasma membrane cholesterol in cystic fibrosis cells correlates with CFTR genotype and depends on de novo cholesterol synthesis Respiratory Research 2010, 11:61

\section{Submit your next manuscript to BioMed Centra and take full advantage of:}

- Convenient online submission

- Thorough peer review

- No space constraints or color figure charges

- Immediate publication on acceptance

- Inclusion in PubMed, CAS, Scopus and Google Scholar

- Research which is freely available for redistribution 